\title{
"Priority of Liberty" and the Design of a Two-Tier Health Care System
}

\author{
FRIEDRICH BREYER \\ University of Konstanz, Konstanz, Germany \\ HARTMUT KLIEMT** \\ Frankfurt School of Finance \& Management, Frankfurt, Germany \\ *Address correspondence to: Hartmut Kliemt , Dr. phil., Sonnemannstrasse 9-11, D-60314 \\ Frankfurt, Germany. E-mail: h.kliemt@fs.de
}

\begin{abstract}
Libertarian views on rights tend to rule out coercive redistribution for purposes of public health care guarantees, whereas liberal conceptions support coercive funding of potentially unlimited access to medical services in the name of medical needs. Taking the "priority of liberty" seriously as supreme political value, a plausible prudential argument can avoid these extremes by providing systematic reasons for both delivering and limiting publicly financed guarantees. Given impending demographic change and rapid technical progress in medicine, only a two-tier system with explicitly limited public guarantees and optional privately financed health services seems acceptable.
\end{abstract}

Keywords:priority of liberty, public guarantees, rationing, sustainability

"The only thing the industrious Beggar has left to conquer those fortified Hearts, if he can walk either with or without Crutches, is to follow close, and with uninterrupted Noise teaze and importune them, to try if he can make them buy their Peace. Thus thousands give Money to Beggars from the same Motive as they pay their Corn-cutter, to walk easy. And many a Half-penny is given to impudent and designedly persecuting Rascals, whom, if it could be done handsomely, a Man would cane with much greater Satisfaction. Yet all this by the Courtesy of the Country is call'd Charity." (Mandeville, [1732] 1988, 293)

"... the power of the mighty hath no foundation but in the opinion and belief of the people." (Hobbes, [1682] 1990, 16)

\section{INTRODUCTION}

Liberal Western welfare states seem to be politically incapable of setting limits to expanding their public health care guarantees. Rapid medical progress 
may render these guarantees unsustainable in the coming decades, which in turn might put the Western liberal orders themselves at risk. At the other extreme, libertarian views on citizens' rights tend to rule out any amount of coercive redistribution for purposes of providing public health care guarantees. In this essay we address the question of what extent of public health care guarantees is compatible with and necessary to preserve the political institutions that embody the "the priority of liberty" as a supreme value of political ethics. We propose to shift the focus of the debate on the "right" public health care system from medical to political concerns. In any event, we will argue that referring to medical needs cannot plausibly serve as an ultimate source of justification of the pubic provision of health services. In terms of the institutional basis of public health care and the coercive taxation necessary to finance it, the pursuit of medical aims cannot be an end but must be treated as a means to political ends.

Subsequently, we will spell out in a "means to ends" framework what it might take to sustain a liberal Western order in the face of increasing conflict between the demands of the principle of "the priority of liberty" on the one hand, and, on the other hand, the demands of "the priority of securing health and survival." That a Western legal order with its priority of liberty could hardly be sustainable if "people were dying in the streets" justifies some public health care provision as a means toward the political end of sustaining the liberal order. That the end could hardly be fulfilled if health care was provided in unlimited quantities of best quality seems also clear. We come to the conclusion that public health care should be provided in limited quantities of fixed quality below market clearing prices, that is, within a "rationing system."

Relying on a concept of rationing as allocating positive but limited amounts of a good (health care) shifts the framing of the resource allocation problem. We are speaking about a limited willingness to give and to assist others as opposed to withholding what is due to them. ${ }^{1}$ If this could be accepted in public discourse, it would facilitate setting limits explicitly and implementing "two-tier medicine" by publicly funded and politically defined ("positive" but) limited guarantees (that may be privately topped up). Considering the impending demographic change and the rapid technical progress in medicine, this is the only financially and politically sustainable way of financing health services in the coming decades while preserving the priority of liberty.

\section{IS NEED-BASED FREE HEALTH CARE ECONOMICALLY SUSTAINABLE?}

Focusing on social policy measures that support survival and health, the marginal contribution of provisions of nutrition, clothing, and shelter are subject to swiftly declining marginal benefits for the recipient's survival 
prospects. This does not apply in the same way to health care provisions. It takes many more resources before the provision of additional diagnostic measures, of emergency care units, and so forth, would cease to enhance survival prospects.

In view of what is medically possible and contributes positively to survival prospects, a distinction between what is "necessary" and what is not has to be made. If this distinction is to be made according to what is deemed "medically necessary" according to the basic values of care that the medical profession endorses, there will be practically no limits to health care expansion, since there are practically unlimited measures that have some medical benefit for the patient.

Given the fundamental coercive power of the state in public health care provision, discretionary power in fixing what is "medically necessary" is much more problematic in the public than in the private sector. Since such discretionary powers in important matters put fundamental political values of rule of law at risk, one may even wonder whether health care provision should be a public task at all. After all, the standard "market failure justification" for public provision does not apply (at least not directly) to health care: health services are goods with very limited externalities that could be provided by markets efficiently (with the exception of preventing contagious diseases). ${ }^{2}$

\section{Health Care Provision as a Means Rather Than an End}

Fundamental externalities arise from the necessity to maintain the rule of law and the prioritized set of liberties created in and by the legal order. Since the maintenance of the legal order is a proper public good that cannot be provided in markets, ${ }^{3}$ there is an intimate if indirect relationship of public health care provision and the public good of maintaining the rule of law. To the extent that maintaining the priority of liberty under rule of law requires health care to be publicly provided, there is a "good non-medical reason" for providing it for every subscriber to the core values of a liberal society.

To put it slightly otherwise, provision of care is necessary to uphold the belief ("opinion" in the initial Hobbes quotation) in the legitimacy of the legal order. Public health care provision is a means to an end rather than an end. At least, if we accept that compulsory taxation may be applied in the provision of public goods at all, we should accept its use as a necessary input for the production of the legal order (assuming, of course, we endorse the desirability of the latter). We then should finance the provision of "rations of care" (i.e., fixed (limited) quantities of health care services-of a standardized quality - made available below market clearing prices) as inputs in the production of the legal order.

The preceding line of argument provides a reason why compulsory redistribution from one individual to another for purposes of health care provision 
can be legitimate to support the "rule of recognition" or opinion of legitimacy of the political order. The justification is framed in terms of political aims, ends, or values rather than in terms of ethical or medical needs. As we illustrate next, once embodied in public discourse, this can make a difference as far as policy implications are concerned.

The Aim of Health Care

According to the received view, the aim of publicly funded health care provision is to prevent sickness and to restore health in case of illness. Since health may be regarded as a so-called "transcendental good," that is, a condition for the pursuit of almost all other goods, one might conclude that health care provision should have high priority for each individual. Yet, conceding this, it should also be noted that concerns common to all individuals need not therefore be public concerns as well. They become legitimate public concerns only if they can be pursued better by collective rather than individual means. Yet the technological externalities of consuming health care services are in themselves negligible (the bulk of health care services provided are not like the malaria net of my neighbor that reduces the likelihood of infection for me as well). In view of the merely minimal externalities going along with them, private provision across markets should be expected to be the most efficient way to provide health services. Typical market failures are largely absent in the provision of health care goods and services. It requires quite a stretch of imagination to treat some persons' inability to pay for the services as a failure of the markets on which these services are provided. Even if somebody could argue that the aims, ends, or values affected are more important in the case of health care than, say, in the case of buying cars, survival may statistically depend as much on whether a person drives either a new Mercedes or a battered Ford when having a car crash, as it depends on her having access to, say, breast cancer screening or not. But who would claim that markets fail in that they do not provide a Mercedes for everybody?

Still, receiving a Mercedes may be seen as analogous to receiving preventive treatment. It is similar to preventive interventions and not to being treated in case of acute sickness. The lack of acuteness of the threat to life and limb induced by a lack of Mercedes cars seem to render the scarcity of such cars more acceptable. The same seems to hold for access to preventive medicine: it can also, despite its possibly large benefits, be lacking without arousing the same emotional responses as a failure to rescue somebody whose life or limb are in imminent danger. For instance, after a car crash occurred, we would think that being rescued would be of paramount importance, because survival is. Indeed, if risks to life or limb are imminent, then the demand for publicly creating an institution that serves the urgent need to be rescued seems much more plausible. 
To the Rescue

Even if not everybody in a society might agree about the need to rescue individuals from imminent serious threats to life or limb, it is still plausible that such agreement will be as widespread as, say, agreement about the need to publicly protect persons' bodily integrity against deliberate (or inconsiderate) violations by others. Those who agree that the state should guarantee the protection of personal spheres against aggression by organs of the state or by other citizens tend to agree also that some guarantees to be rescued in cases of imminent threats to life or limb should be provided. For obvious reasons, protection against starving, freezing, and so forth, are provided in rich Western countries as well.

The effects of the aforementioned kinds of services seem similar to citizens. They will lump them together. The person who is threatened by the villain will expect instantaneous help, whenever possible and close by; the person who is threatened by starvation or freezing will expect food or shelter, if available. Similarly, the person whose life is under threat due to an illness or accident from which rescue is possible by some state organ or other will expect this. Moreover, and more importantly, citizens in their roles as bystanders rather than victims will expect the state to come to the rescue, if possible, in cases of imminent risk to life or limb. They will expressively vote "to buy their peace" and "ease of conscience" (Mandeville, [1732] 1988, 293). ${ }^{4}$ They will tend to deem the state illegitimate if it does not provide that peace of mind and ease of conscience.

Taking into account the (psychological) fact that citizens will not regard a developed state as legitimate unless it can provide such basic protection, there is a good reason to subscribe politically to the so-called "rescue-principle" as defining a state obligation. If threats to life and limb are serious, imminent, and can be prevented by collective intervention through the state at "non-excessive" costs, the rescue principle seems rather plausible. It is the acuteness of the threat along with the productivity of the state in providing guarantees of the relevant "protective" services rather than anything else that matters. Any more distant or unforeseeable risks to life and limb are, across the board, of lesser priority. A hundred specific lives to be rescued "now" tend to outweigh a thousand or ten thousand statistical lives "twelve-months hence." And, politically the "now" also counts more than the more distant consequences.

\section{Political Priority Setting in Health Care Provision}

If individuals are not primarily concerned with health as such but rather with the symbolic meanings of "coming to the rescue," the issues become even more straightforwardly rather than medical. What is at stake is the protection of the belief in the legitimacy of the legal order and thus a proper public rather than private good. The more imminent, the more certain and the more 
serious a risk to life and limb is, the more urgent the provision of some help will seem to the public at large.

For instance, it might be possible to spend money either on bypass surgery or on chemotherapies for terminal cancer patients beyond a certain age limit. For the sake of specificity, assume that a typical bypass graft reduces the probability of a lethal event within the following 5 years from, say, $70 \%$ to $40 \%$. Measures of quality-of-life-years (QALYs), disability-adjusted-lifeyears or whatever might indicate that this bypass surgery is the superior way to spend the money as compared to spending it on chemotherapies. Yet the conventional medically motivated measures are not the only relevant concerns, and politically speaking not even the most relevant ones. Political priority setting tends to be urgency-related and thus to depend more on factors like concreteness and closeness of risks than on conventional measures of policy evaluation. And this is relevant for the political ethical comparison of bypass surgery and chemotherapy as well.

Should public funding not be provided for bypass surgery, the effect would be probabilistic. The probability of a lethal event would increase for those who would not get access to surgery due to a lack of funds or willingness to pay. Still, for any given individual the relationship between the non-provision of the service and the lethal outcome within the following 5 years would remain stochastic and the ascription of responsibility for the outcome "vague." If, on the other hand, chemotherapies were not financed, the result would be, in a way, deterministic; responsibility for the outcome could be straightforwardly ascribed. The patient would die sooner almost with certainty. Hence, reducing the chance of survival by not funding heart surgery may-independently of expert opinion on its relative medical merits-be more acceptable than not financing the chemotherapy for terminal cancer patients.

The reason lies in the well-known fact that humans seem to show rather different attitudes toward statistical lives and statistical risks on the one side and toward identifiable concrete lives and concrete risks on the other. This may seem irrational from some points of view. In particular, if we try to rationally design institutions such that they will provide the best returns on investment as measured in, say, QALYs, such a preference for identifiable concrete conditions (thus opting for the chemotherapy) may be treated as "irrational." However, if we frame the problem in terms of political necessities that arise from the moral aim to protect the integrity of the liberal legal order rather than medical needs according to expert opinion, the symbolic aspects of policy making must not be neglected. In such fundamental matters as providing some protection against imminent threats to life and limb, symbolic aspects rather than statistical medical criteria are the essence of the political problem that arises in pursuit of protecting prioritized liberty. One could go even further and argue that even if life is not threatened but only a rather fundamental direct reduction of quality of life is at stake (in 
cases where the capacity to walk is lost), symbolic aspects of the concrete and visible may prevail. For instance, a hip replacement that is deterministically related to preventing immobility of the patient may be less effective as measured in cost per QALY than the heart surgery. Even though that hip replacement may not even significantly prolong a patient's life, nevertheless its provision will be preferred by bystanders to an extent that makes it politically necessary, whereas providing some kind of heart surgery remains politically unnecessary.

To summarize, health care is as such a typical private good. Its public provision cannot be justified by its medical characteristics, since the medical characteristics suggest private provision: in public discourse, public guarantees should be justified in terms of political externalities rather than private medical benefits. This avoids the risk that the invocation of medical needs alone will lead its addressees astray toward unlimited need-based guarantees. Though a proper cost-benefit analysis as performed by health economists is clearly superior to invoking medical needs regardless of costs, that analysis also neglects the political (economy) rationale of symbolic health care provision. Decisions to provide health care by means of the state's fundamental coercive power to tax, just as decisions to set limits to such provision, should be presented in public discourse as primarily political decisions which are directly related to the most basic political values of a liberal order.

Lamenting the dismal state of public discourse is one thing, suggesting policy alternatives that could express the ideals of solidarity and personal responsibility in ways that are in line with the fundamental principles of priority of liberty under rule of law another. An "informed common sense" type political argument may perhaps help to influence the general view on political legitimacy in a politically sustainable direction respectful of the priority of liberty.

\section{WHAT TO DO WITH HEALTH CARE GUARANTEES?}

Even if somebody personally feels under an obligation to transfer income to the so-called "third world," he might regard it as illegitimate if the state uses its own fundamental coercive power to force others to fulfill an obligation they possibly do not accept. Even if we accepted a metaethical position allowing for a right-based theory ${ }^{6}$ in which rights constitute obligations (and not vice versa) and even if we should concede the utilitarian arguments of Peter Singer, Peter Unger, or, more recently, Joshua Greene ${ }^{7}$ that we must help strangers simply because they are humans and suffer, we might hesitate to impose our views on others. As long as we endorse norms of interpersonal-political respect and the priority of liberty, we have good reasons to argue politically rather than on the basis of universal rights or a shared humanity as such. Even proponents of those liberal ethical positions 
that do imply ethical obligations to assist outsiders ("full" strangers) should still agree that norms of interpersonal-political respect prohibit using the fundamental coercive power of the state to impose a specific "conception of good" on others.

If it comes to political ethics in dealing with the fundamental coercive power of the state, it matters whether those supposed to be obliged are living under the same sovereign monopoly of coercive power or not. Coercion in favor of those who are subjects of the same monopoly of power is different from coercion in favor of those who are not subjects of the same sovereign legal order.

\section{Separating Survival and Financial Aspects}

"Social justice conceptions of providing care" tend to confuse protection against an imminent risk to life or limb with protection against the financial risks of illness. A simple thought experiment concerning unconditional credit guarantees for medical treatments in case of urgent need can illustrate what is at stake here. If the state declared a commitment to grant credit for health care expenses, those who need treatment could go ahead and buy it on credit. In such a "buy now, pay later" system of guarantees, the general public would guarantee to take over the costs initially but would charge the recipients of credit up to the poverty line afterwards. Nobody would die due to an inability to pay for health care services. However, after surviving the imminent threat to life or limb, persons rescued would possibly be ruined financially unless they had bought insurance beforehand. This would provide an incentive for citizens to insure themselves against the financial risks of illness, despite the unconditional character of the state guarantees.

The scheme of unconditional credit guarantees would assure that the socialist principle "from each according to his abilities, to each according to his needs" would be honored. However, regrettably, this rather elegant way of separating the two dimensions of solidarity in securing survival and solidarity in financial matters is not workable. Those who receive help and are afterwards unable to repay cannot be charged beyond the minimum income level that is guaranteed in society. People with very low incomes to start with and people who ran into debt due to relying on the public guarantees for health care provision would afterwards have every incentive to use the public funds to their limit, and physicians would have an incentive to help them to free-ride.

In view of the fact that the less well-to-do and less well educated-conditions that typically occur in tandem-have a lower life expectancy anyway, the invitation to exploit the unconditional guarantee system may be seen as a kind of compensation for "general social inequality." "Whether one accepts that kind of argument or not, the incentives for patients and doctors will be such that quite extreme social waste of resources will emerge. Whatever its 
other merits, the finances and the political economy of a scheme of unconditional credit-based solidarity seem almost as hopeless as the unlimited unconditional solidarity at the taxpayer's expense that is presently the official policy. Some willingness to put a political cap or limit on need-based solidarity in health care provision is required.

\section{A Two-Tier System}

Once the standard of what is to be publicly provided and what not has been fixed in a list of condition-treatment pairs-or, for the purposes at hand, equivalently, diagnosis-treatment pairs-the public could guarantee that the items included in that list would be provided as rations of care at the general taxpayer's expense. Any additional services would have to be paid by the patients themselves.

This scheme can work to the extent that the general public would be willing to openly acknowledge the limits to its solidarity by guaranteeing the standard for everybody but not more. This would amount to explicit egalitarian rationing in that all citizens would unconditionally receive limited guarantees, that is, fixed amounts of services below market clearing prices and possibly at zero costs. Beyond the explicitly fixed standard of solidarity to be provided by the cheapest care provider, patients could be free to contract for additional services or another service provider against surcharge (laying the foundation for competition among providers).

As long as patients are free to buy additional services and the standard of services is well defined, a two-tier system of health care provision can work. The system would include a-possibly and in all likelihood very high-politically defined minimum standard for everybody. In that sense it would be egalitarian. In other regards, it would allow for inequality, since nonstandard treatment would be available only to those who would be willing and able to pay for it.?

Presumably, what is to be included in the "standard health plan" as a publicly guaranteed "right" and what not, would be dictated by the rescue principle (implying an overall result rather close to the well-known Oregon health plan in its later incarnations). Although initially such a solution might seem quite egalitarian, in all likelihood it will be increasingly less so as medical technology develops further (see section $\mathrm{V}$ below). It may be harder to achieve political feasibility and sustainability for such a plan than it might seem at first sight.

\section{THE INEFFICIENCY OF CONCEALED RATIONING IN THE GERMAN SYSTEM}

Like other "noble lies," the attempt to conceal the fact that unlimited guarantees to free health care services are unsustainable leads to severe distortions. The effects can be seen in all Western welfare states, and they show most 
obviously in waiting lists (at least) for elective health services such as orthopedic surgery, which are in place in the United Kingdom and in Sweden. In other countries such as Germany, waiting and delay are less obvious because physicians and hospitals have chosen to use other means of limiting access to scarce health care resources. ${ }^{10}$ Whatever the means of camouflage, the fiction of access independently of willingness and ability to pay from the private purse is maintained: "yes', the patient has to wait but will get access according to need," "'yes', there are certain things that the patient might not receive yet they are "not really necessary'," and so forth.

Ironically, a direct effect of this attempt to avoid transparency in rationing by an explicit benefit package in social health insurance (SHI) leads to an even more drastic type of two-tier medicine. For, measures such as deferral into the next calendar year or denial that a treatment would offer potential benefits apply to patients in SHI, but not in private health insurance (PHI). Moreover, since PHI reimbursement rates for similar services are considerably higher than in SHI, physicians and hospitals will always find ways to provide the demanded services to privately insured patients with priority.

What makes this unavowed German two-tier medicine especially problematic from an ethical point of view is that relatively few German citizens have the choice between membership in SHI and membership in PHI. For children, membership is determined by birth because it depends on the membership of the parents. Adults have a choice only if their earnings exceed a certain level (which is fixed at some 1.6 times the average earnings) or if they are members of certain occupational groups (such as medical doctors). Moreover, people with high earnings have an incentive to choose PHI, in particular if they are low risk, because contributions are risk-rated in PHI, but community-rated in SHI. As a consequence, those who have been favored by nature with good health and high human capital get the additional advantage of better medical care without having to pay more than in SHI.

This arrangement is not only inequitable by almost any standards, but also inefficient. The root cause of the inefficiency is that politicians refuse to specify explicitly the limits of the benefit package to which the insured has a legal claim. For the lack of well-defined limits to the SHI packages prevents the emergence of efficiency enhancing private insurance companies offering supplementary coverage for specific services not provided by SHI. As the probability of suffering from concealed limitations increases with the probability of illness, it is the part of the population with high risk of illness (and in particular those with middle incomes), who would purchase these supplementary insurance contracts but cannot do so at efficient prices. They are those who are harmed the most by the refusal of politicians to admit that the limiting aspect of rationing is inevitable and omnipresent. 


\section{SUSTAINABILITY OF HEALTH CARE FINANCING}

The inefficiency and inequity caused by the system of concealed limit setting described above must become more severe in the future, since demographic change and medical progress will widen the gap between medical possibilities and financial means. Over the last decade, a large and growing health economics literature has focused on the question whether the aging of the population will by itself raise or lower the per-capita demand for health services. ${ }^{11}$ However, even if the answer to this particular question turned out to be appeasing, the other two effects will clearly increase the sustainability gap: the decreasing share of the working-age population will limit future financial means and the trend of increasing the supply of potentially lifeprolonging innovations in medical technology will certainly continue. After all, Nobel prizes in Medicine are awarded for breakthroughs in (typically very costly innovative) technology rather than advances in cost-saving. ${ }^{12}$

The public debate on setting limits on governments' promises with respect to future health care services is dominated by two opposing lines of argument: the defenders of the present, pay-as-you-go financed SHI systems denounce any such limits as unethical and as discriminating against the aged who are taken to be the main beneficiaries of unlimited promises. Opponents, in contrast, address the question of intergenerational equity. They argue that the obligation to honor these claims might be unjust toward future generations of workers. Both lines of argument tend to overlook feasibility issues. It is very likely that future generations might simply refuse to honor the alleged "obligations," be it through tax evasion, through emigration or more directly by voting to cut the benefits in SHI. These events are more likely than is conventionally assumed. For instance, emigration of the very highest group of earners will take place if the tax burden is increased too much. As a consequence, the tax burden caused by health expenses must go up even more, the competitiveness of an economy like the German will shrink, and even more high potentials will leave. Even though the composition of the pool of voters will shift toward older and older median voters, it is unclear what the implications will be. In particular, if the older individuals insist on getting their promises fulfilled, the unsustainability described before will be even enhanced. In all likelihood, the victims of intergenerational "inequities" will not be the future young, but the future old. Or else, the young as well as the old will suffer if, in response to the problems described, states become more restrictive and perhaps even abandon such basic principles like freedom of exit.

In view of the precarious character of intergenerational promises, it seems a requirement both of political fairness and prudence to reduce the extent of public provision of care to what is compatible with upholding political stability. The rescue principle may be used as a broad guidance in determining the necessary minimum: a priority for measures to eliminate direct and 
imminent threats to life or limb while neglecting more remote, especially statistical risks. Combined with implementing a "futility threshold" cutting off very low increases of the likelihood to be rescued and/or low lifespans gained, such an approach might lead to acceptable and politically enforceable explicit limits to health care guarantees. This would make the system more sustainable and efficient by paving the way for the emergence of supplementary health insurance contracts. These can be used by those who are willing to spend their own resources at their own opportunity costs to gain better access to health care services than what is guaranteed for and by the public at large.

Admittedly, even if the necessary condition of putting explicit limits to care guarantees in place could be met, the development of long-term insurance contracts will not be a simple task. As medical technology 30 years down the road cannot be foreseen today, the terms of these contracts cannot be very detailed. Maybe they can only consist of Medical Savings Accounts with fairly general rules as to what circumstances would allow one to draw benefits from these accounts. It may also be that we can and perhaps should simply publicly guarantee a standard of health care as presently reached. The publicly guaranteed package would then be defined according to present rather than future technology, while leaving everything else to private citizens and their initiative. But such a "defined benefits" approach may be unsatisfactory since participation in technological progress is generally considered to be highly desirable. The question remains open how future private insurances could be built such as to cover some guaranteed participation in medical progress even in the face of radical uncertainty.

All these difficulties must be admitted. Yet, given present public opinion and public policy dynamics, theorists of medical cum political ethics have the responsibility to explore such alternatives rather than defend the demands of their ideal ethical theories until a deep crisis emerges. In such a crisis unsustainable public health care guarantees would pit the survival chances of identifiable groups against the survival chances of identifiable other groups, thus placing the freedom of Western-type legal orders at risk. In the name of some short-sighted lifeboat ethics or other, rule of law and the priority of liberty may then be lost. Once they are lost, in all likelihood society will end up economically impoverished as well. It will be impossible to sustain the policy measures that let the "rescue principle" overrule fundamental rule of law and liberty constraints.

In sum, guidance by the rescue principle in defining the basic basket of health care guarantees must be constrained by the requirements of rule of law and the priority of liberty. Accepting this constraint is itself a matter of prudence if one subscribes to the empirical view that societies not meeting minimum requirements of rule of law and the priority of liberty will not be wealthy enough to provide for the health care of the future. 


\section{THE GOODS OF RATIONING}

In line with Mandeville's view cited in the preamble, political urgency could be defined according to the feelings of the individual citizens who desire that the "streets" not be "littered" with "dying people." Less cynically put, the belief in the legitimacy of a legal order in which respect for the human individual and his integrity ranges supreme requires as a matter of political psychology that some basic health care be provided. In order to take liberal principles seriously, public, tax-financed provision should not be maximized but rather minimized to what is politically indispensable. However, most of the public as well as philosophical debates today still take for granted that it is a public task to provide maximal guarantees of access to state-of-the-art health services for "all citizens" according to their medical needs independently of their ability and willingness to pay.

The prevailing question of the public debate is not what an individual would rationally do for himself but cannot do well (thus appealing to the principle of subsidiarity). Today, that prevailing question focuses rather on what society could do for its citizens in optimizing their lives. Such an approach amounts to loading the dice in favor of redistribution. The general proclivity to explicate the concept of rationing in terms "of withholding care to be expected of net benefit for the patient" (see Buchanan, 1997, 335ff) forms the most striking expression of this proclivity. The latent suspicion of illegitimacy is slipped in by the use of the term "withholding." The situation is framed such that a patient has a prima facie claim to receive care solely for the reason that it is expected to be of net benefit.

Such a conceptualization of "rationing" is not in line with our experience and common sense. Just imagine rationing in times of war. Say, a queue forms in which people line up to receive a rationed good once they reach the head of the queue. They certainly do not line up because they expect that something will be withheld from them once it is their turn. They know that when reaching the head of the queue they will get some, albeit only a limited quantity of the good they desire. They are willing to incur the (opportunity) costs of waiting time because they expect to receive their ration at a price lower than the one they would have to pay at that time for the same quantity on a legal or illegal spot market.

Properly understood, rationing is not a measure of last resort in times of war or extreme scarcity. On the contrary, applying the more reasonable concept of rationing as limited giving below market clearing prices (at the time of resource allocation) illustrates the desirability of rationing. Anybody who enters an insurance contract, say, with a health maintenance organization, $\mathrm{HMO}$, does so because he prefers to take part in a rationing scheme rather than buying services on the spot at full market prices when the need for these services arises. The contract specifies terms of service that will be rendered according to some standard or judgment of need rather than direct willingness to pay for service when the need arises. To constitute such obligations and claim rights is the whole point of insurance. The insured bought 
into "rationing" freely, since it is clear that the promise to grant help as issued by the HMO is a limited one (and despite the patients' rights movement, it is known and accepted to be limited in principle in and out of court).

Public guarantees of "rations of health care" are often called "public insurance." This is misleading in that the guaranteed (or promised) services are neither voluntarily paid for nor limited. It would be more appropriate to call them by the name of earmarked taxes. It is an analytical truth that taxes—other than insurance contracts—are "engaged" nonvoluntarily. And, there should be a collective good or an externality involved whenever taxes are legitimately imposed. In case of the health interests of another citizen, the relevant externality justifying coercive collective provision is not easily found. In view of the properties of health care, sustaining a system embodying the priority of liberty under rule of law is arguably the only plausible externality. To institute measures that will support political stability rather than to promote health, to induce people to uphold their acceptance of the legal order rather than to help them live better or longer lives, to promote peace rather than justice in society-these are legitimate goals for which resources should be redistributed in and by tax-funded public health care. Though apparently trivial, such a shift in perspective could have far-reaching implications for the organization of society and the role of health care in it. Such a shift would facilitate setting limits with regard to ends that-unlike solidarity with the needs of the sick-naturally allow for limitations. Equal claims to limited rations of public solidarity in health care will be financed by taxes, while anything that goes beyond will be the private responsibility of individuals. As long as the rescue principle is taken account of to an appropriate extent within the constraints of rule of law and the priority of liberty, such a two-tier scheme can presumably be acceptable politically at least in the West. In any event, that is what we must hope for if we endorse the hope of living in a free society under the rule of law in the future.

\section{NOTES}

1. Though this may amount to beating to death the obvious, let us reiterate that rationing in the narrow sense of the term always arises in the presence of two central conditions: 1. A willingness to give something voluntarily to which the recipient has no independent (legal) claim, 2 . The willingness to give is limited and typically lower than optimal from the point of view of the recipient.

2. Therefore, within a standard welfare economic and political philosophy framework, plausible reasons for public health care guarantees must be of a political rather than "medical" nature. To put it even more bluntly, political ethics has priority over medical ethics here.

3. At least we do not accept the anarchist claim that there could be a market for order that would not rely already on some form of order.

4. On expressive voting, see Brennan and Lomasky (1993), 183-206.

5. This is, of course, alluding to one of the most important arguments in all political philosophy expanded on by David Hume in the Treatise (Hume, [1739] 1898) (book III, part II, section viii).

6. See Mackie (1978).

7. See for instance (Unger, 1996; Singer, 2011; Greene, 2013).

8. See Waldron (2008) for the United States and Gaudecker and Scholz (2007) for Germany. 
9. Medical savings accounts of some type or other might soften the limit, yet in the end certain treatments would be available only to those able to pay cash or insurance premiums for them. From a classical liberal point of view "legal limit setting" is discussed in Buchanan ([1975] 1999), Kliemt (1993), Zajak (1995).

10. For a detailed description, see Strech, Synofzik, and Marckmann (2008).

11. For a recent survey, see Breyer, Costa-Font, and Felder (2010).

12. See examples from Fleck (2009), Chapter 6.

\section{ACKNOWLEDGMENTS}

We would like to express our gratitude to Corinna Delkeskamp-Hayes and two anonymous referees for their helpful suggestions, to Katharina Brütt and Sarah-Lea Effert for their assistance, and the DFG (German Science Foundation) for supporting related research in priority setting in health care in the research group FOR 655 .

\section{REFERENCES}

Brennan, H. G. and L. E. Lomasky. 1993. Democracy and Decision. Cambridge: Cambridge University Press.

Breyer, F., J. Costa-Font, and S. Felder. 2010. Ageing, health and health care. Oxford Review of Economic Policy 26:674-90.

Buchanan, A. 1997. Health-care delivery and resource allocation. In Medical Ethics, ed. R. M. Veatch, 321-61. New York: Jones and Bartlett.

Buchanan, J. M. (1975) 1999. The Limits of Liberty. Vol. 7 of The Collected Works of James M. Buchanan. Indianapolis, IN: LibertyPress.

Fleck, L. 2009. Just Caring: Health Care Rationing and Democratic Deliberation. Oxford: Oxford University Press.

Gaudecker, H.-M. v., and R. D. Scholz. 2007. Differential mortality by lifetime earnings in Germany. Demographic Research 17:83-108.

Greene, J. D. 2013. Moral Tribes: Emotion, Reason, and the Gap Between Us and Them. New York: Penguin.

Hobbes, T. (1682) 1990. Behemoth. Chicago: University of Chicago Press.

Hume, D. (1739) 1898. A Treatise of Human Nature. Oxford: Oxford University Press.

Kliemt, H. 1993. On justifying a minimum welfare state. Journal of Constitutional Political Economy 4.2:159-72.

Mackie, J. L. 1978. Can there be a right-based moral theory? Midwest Studies in Philosophy 3:350-59.

Mandeville, B. (1732) 1988. The Fable of the Bees or Private Vices, Publick Benefits, With a Commentary Critical, Historical, and Explanatory by F. B. Kaye. Indianapolis, IN: Liberty Fund.

Singer, P. 2011. Practical Ethics. New York: Cambridge University Press.

Strech, D., M. Synofzik, and G. Marckmann. 2008. How physicians allocate scarce resources at the bedside: A systematic review of qualitative studies. Journal of Medicine and Philosophy 33:80-99.

Unger, P. K. 1996. Living High and Letting Die: Our Illusion of Innocence. New York: Oxford University Press.

Waldron, H. 2008. Trends in mortality differentials and life expectancy for male social securitycovered workers, by socioeconomic status. Social Security Bulletin 67 (3).

Zajak, E. 1995. Political Economy of Fairness. Cambridge, MA: MIT Press. 